\title{
Frequency- and density-dependent selection in wheat powdery mildew
}

\author{
ROBERT B. O'HARA* \& JAMES K. M. BROWN \\ Cereals Research Department, John Innes Centre, Colney Lane, Norwich NR4 7UH, U.K.
}

\begin{abstract}
The effects of different initial densities and isolate frequencies on three pairs of isolates of Erysiphe graminis f. sp. tritici, the fungus which causes powdery mildew in wheat, were investigated in competition experiments. There was no evidence for frequency-dependent selection, which suggests that competition between colonies is not affected by genotype. Density-dependent selection was consistently found. For one pair of isolates it was shown that the logarithm of the selection coefficient varied linearly with the logarithm of density, and the greatest changes in selection occurred over the lower density changes. Investigation of life history traits showed that the observed differences in selection may have been caused by differences between isolates in the effect of density on spore production.
\end{abstract}

Keywords: density-dependent selection, Erysiphe graminis f. sp. tritici, frequency-dependent selection, wheat powdery mildew.

\section{Introduction}

Cereal powdery mildew, caused by the ascomycete fungus Erysiphe graminis, is a major disease of cereal crops in temperate climates. For most of the year the pathogen reproduces clonally by producing conidiospores. Because of its importance, and the fact that the genetics of resistance and virulence are well characterized, following the gene-for-gene system (Jørgensen, 1988), it has become a model for studying the epidemiology and population genetics of foliar diseases (Brown, 1994).

Because of the explosive growth of mildew epidemics during the host's growing season, the densities of colonies on plants change considerably as the crop develops. Colony density affects the growth of mildew, and the magnitude of this effect varies between isolates (see below). The changes in density seen as the epidemic progresses may mean that different isolates are favoured in different phases of the epidemic, and thus density may play a part in maintaining genetic diversity.

The theory of density-dependent selection has been constructed in terms of $r$ and $K$ selection (e.g. Charlesworth, 1971; Roughgarden, 1971; Clarke, 1972), where organisms differ in their fitness because of differences in their growth rate $(r)$ or carrying capacity $(K)$. It is generally assumed that there is a trade-off between these two strategies, and

${ }^{*}$ Correspondence and present address: Environmental Science and Technology Department, Ris $\varnothing$ National Laboratory, Post Box 49, DK-4000 Roskilde, Denmark. that individuals will lie somewhere along the continuum between the extremes of rapid growth and efficient use of resources. If the population density changes then selection can change to favour either of these two extremes.

Density-dependent selection has been shown to occur in several organisms, such as Drosophila (e.g. Lewontin, 1955; Mueller et al., 1991), mosquitoes (Bradshaw \& Holzapfel, 1989) and the barley leaf rust fungus, Puccinia hordei (Falahati-Rastegar et al., 1981, 1983). In barley leaf rust, Falahati-Rastegar et al. (1983) showed that at low pustule densities, the fitter isolates were those which produced more spores, whereas at high density the fitter isolates were those which were quicker at penetrating stomata. The effects of density on sporulation have been investigated for several plant pathogens, including bean rust, Uromyces phaseoli (Imhoff et al., 1982), and oat stem rust, Puccinia graminis f. sp. avenae (Leonard, 1969a) as well as cereal mildews. In all cases, sporulation decreased with density.

The effects of density on life history traits have been investigated in the cereal powdery mildews. Carver \& Ingerson-Morris (1989) showed that infection efficiency of one isolate of oat mildew, caused by $E$. graminis f. sp. avenae, decreased with increasing inoculation density. Aust and Kranz (1974), using a mixed population of the barley mildew pathogen, E. graminis f. sp. hordei, showed that infection efficiency was not affected by density, but that latent period fell as density increased. Rouse $e t$ al. (1984) studied spore production in two isolates of 
E. graminis f. sp. tritici (wheat mildew). They showed that spore production per leaf increased up to a density of about 25 colonies per leaf, and then decreased. No direct comparison was made between the two isolates, but a visual examination of the graphs of spore production against colony density (fig. 3 in Rouse et al., 1984) suggests that the two isolates differed in their reactions to density, particularly on the variety Knox, where the reduction in the spore production per colony was much less for one isolate than for the other. Stähle (1986), comparing different isolates of $E$. graminis $\mathrm{f}$. sp. hordei, found no effect of inoculum density on latent period, but inoculation efficiency and sporulation were both reduced at a higher density, and also different isolates were affected to different extents by changes in density. However, none of these studies investigated competition between isolates directly.

Frequency-dependent selection may be driven by either intraspecies interactions (e.g. sexual selection), or interspecies interactions (e.g. host-parasite systems). Experimental evidence for frequencydependent selection was reviewed by Antonovics \& Kareiva (1988). Two-species models of frequencydependent selection in plant-pathogen interactions have been proposed (e.g. Jayakar, 1970; Leonard, 1977; Barrett, 1988). We are not aware of any research on frequency-dependent selection in cereal mildews, but Welz et al. (1990) argued that it may have occurred in a field plot, when the frequency of one race repeatedly rose to about 70 per cent, but not higher.

One of the notable features of field populations of $E$. graminis is that they are usually very diverse (Brown, 1994). This diversity could, under some conditions, be maintained by frequency- and/or density-dependent selection (Hedrick, 1985). The study reported here was designed to investigate whether these types of selection occur in E. graminis, how selection depends on the initial conditions and what life history traits are affected by the different conditions.

\section{Methods and materials}

\section{Selection experiments}

Experiments were carried out using five isolates of E. graminis f. sp. hordei - JIW9 (having the virulences V1, V3c and V8) and JIW45 (V2, V3a, V4a, V4b, V5 and V8), which are white, and JIW20 (V1, V2, V3a, V4a, V4b, V5 and V9), JIW19 (V1, V2, V3a, V4a, V4b, V5 and V6) and JIW24 (V1, V2,
V3c, V7 and V9), which are pink to brown in colour. For each experiment a pair of isolates was used, one white and one pink, so that mature colonies could be distinguished easily from each other. JIW45 was paired with JIW20. JIW9 was paired initially with JIW19, but after the latter isolate died JIW24 was used instead. The wheat variety Cerco, which has no resistance alleles (Bennett \& Van Kints, 1982), was used throughout. Leaf segments, $2.5 \mathrm{~cm}$ long, of first seedling leaves (prophylls) were laid adaxial side upwards on water agar $\left(5 \mathrm{~g} \mathrm{~L}^{-1}\right.$ containing $0.1 \mathrm{~g} \mathrm{~L}^{-1}$ benzimidazole) in clear plastic boxes. Each box contained about 35 leaf segments. Leaves were inoculated in a settling tower, $31 \mathrm{~cm}$ in diameter, by the method of Brown \& Wolfe (1990). Inoculated boxes were incubated in a controlled environment cabinet at a temperature of $15^{\circ} \mathrm{C}$, with a $16 \mathrm{~h}$ day $/ 8 \mathrm{~h}$ night cycle.

The form of the experiments on both frequencyand density-dependent fitness was the same. Mixtures of spores were inoculated onto five boxes of leaves at different frequencies or densities, with treatments being replicated by making two or three inoculations at each density. After 12 days, the inoculation frequencies of each isolate were estimated by counting the number of colonies of each colour in the boxes which had been inoculated at low density. Typically 100-200 colonies were scored per inoculation. In order to estimate the frequency of spores of each isolate after one generation of selection, 14 days after inoculation spores were tapped from leaf segments of each box onto paper and inoculated onto another box of leaves at a low enough density for individual colonies to be easily distinguished. After 12 days incubation, the number of colonies of each colour was counted.

\section{Frequency-dependence experiments}

Spores were mixed in different proportions (shown in Table 1) and inoculated at densities between 200 and 260 spores $\mathrm{mm}^{-2}$. Densities of inoculation were estimated by placing microscope slides in the inoculation towers, and counting the number of spores in 24 fields of a $1 \mathrm{~cm}^{2}$ graticule at either $\times 100$ or $\times 400$ magnification. In order to estimate the initial frequencies, two boxes of leaves per isolate mixture were inoculated at a low density.

\section{Density-dependence experiments}

Spores were mixed together in approximately equal proportions for the initial inoculations. Initial frequencies of the two isolates were estimated by 
Table 1 Results of frequency-dependent selection experiments or wheat powdery mildew, given as the proportion of JIW9

\begin{tabular}{llcccccc}
\hline Experiment & Frequency & $\begin{array}{c}\text { Initial } \\
\text { proportion } \\
\text { (per cent) }\end{array}$ & $n^{*}$ & $\begin{array}{c}\text { Standard } \\
\text { error }\end{array}$ & $\begin{array}{c}\text { Final } \\
\text { proportion } \\
\text { (per cent) }\end{array}$ & $n^{*}$ & $\begin{array}{c}\text { Standard } \\
\text { error }\end{array}$ \\
\hline 1 & Low & 40.4 & 89 & 1.6 & 74.3 & 7305 & 0.41 \\
2 & High & 91.8 & 196 & 0.6 & 97.0 & 5652 & 0.10 \\
& Low & 10.9 & 247 & 2.2 & 48.9 & 1539 & 0.94 \\
& High & 76.5 & 132 & 5.8 & 92.6 & 1489 & 0.27 \\
\hline
\end{tabular}

* Number of colonies scored.

scoring colonies from the low density inoculations. One series of experiments used two densities, with averages of $0.31( \pm 0.19)$ spores $\mathrm{mm}^{-2}$ at the low density, and $580( \pm 160)$ spores $\mathrm{mm}^{-2}$ at high density. In another series of experiments, several densities over the range described above were used.

\section{Analysis}

Haldane (1924) proposed a model for selection in asexual populations, which is also described by Leonard (1969b). For one generation this reduces to the following expression:

$\log \frac{p_{1}}{\left(1-p_{1}\right)}=\log \frac{p_{0}}{\left(1-p_{0}\right)}-\log (1-s)$

where $p_{0}$ and $p_{1}$ are the proportions of one type of isolate in generations 0 (before selection) and 1 (after selection), and $s$ is the coefficient of selection against that isolate relative to the other. This is equivalent to modelling the data as a contingency table where colonies are classified by isolate and density or frequency (Cox, 1970). If the interaction term is significant, then there are differences in fitness. Analysis was carried out by generalized linear modelling (McCullagh \& Nelder, 1983) using the statistical package GENSTAT 5, version 3.2 (Numerical Algorithms Group, Oxford).

\section{Life history traits}

Two parameters affecting the life histories of the isolates, infection efficiency and spore production, were estimated. These would both directly affect selection after 14 days, whereas other traits such as latent period would only have an indirect effect. Boxes of Cerco leaf segments were inoculated at low and medium densities (at averages of 0.41 and 5.3 spores $\mathrm{mm}^{-2}$, respectively). At higher densities it would have been impossible to discern individual colonies. After seven days, the number of colonies on each leaf was counted, and the area of the leaf surface was measured. After 14 days, spore production per colony was estimated by collecting spores from about 55 colonies and estimating the number of spores by inoculating them onto a microscope slide in a settling tower, and counting the number of spores on the slide. Infection efficiency was calculated as the number of colonies produced per leaf unit area divided by the inoculation density, and the spore production was estimated as the spore density per colony multiplied by the area of the base of the inoculation tower.

\section{Results}

\section{Selection experiments}

Frequency-dependent selection The results of two frequency-dependent selection experiments are shown in Table 1. Although it is clear that there is selection in favour of JIW9, statistical analysis is needed to see if selection changes with frequency. The structure of the generalized linear model analysis is similar to that of a more standard ANOVA. Frequency-dependent selection is represented by the Time by Isolate by Frequency interaction (i.e. differences in the change of the proportions of the two isolates depending on the initial frequencies). Because we had replicate inoculations nested within each frequency group, there is also a Time by Isolate by Frequency by Inoculation term. All other terms in the analysis are 'nuisance effects' and are not shown.

The standard analysis would be to compare the deviance of each term against a $\chi^{2}$-distribution. However, in most of the experiments, the residual term (i.e. the Time by Isolate by Frequency by Box within Inoculation term, the variation between boxes within inoculations) is significant, which suggests that the variation between boxes within each inocu- 
lation was larger than expected from the model. Therefore, as an alternative, the deviance ratio was used. This compares each term with the residual term, and approximately follows an $F$-distribution. When the residual was not significant, the two tests gave similar results.

The analysis of the four experiments is shown in Table 2. Different inoculations did not behave differently. The data showed no evidence for frequency-dependent selection in any of the experiments.

Density-dependent selection The results of the density-dependent selection experiments carried out at two densities are shown in Table 3. Because the initial proportions of the isolates in an experiment were equal, it is not necessary to use time as a factor. Therefore, only the frequencies after the second inoculation (i.e. after one generation of selection) were compared. In the analysis, this is the Isolate by Density interaction. As with the frequency-dependent selection analysis, there were replicate inoculations nested within the density treatments. These appear in Table 4 as the Isolate by Density by Inoculation term. Like the frequencydependence experiments, when a range of densities was tested, only one inoculation per density was carried out, so this term does not appear in the analysis. The deviance ratio was used to test for significance, again like the frequency-dependent selection experiments.

The analysis of all the experiments is shown in

Table 2 Significance tests for the presence of frequency-dependent selection on wheat powdery mildew

\begin{tabular}{lccccccc}
\hline Experiment & Isolates & $\begin{array}{c}\text { Deviance ratio*, } \\
\text { Time by Isolate } \\
\text { by Frequency }\end{array}$ & d.f. & $P \dagger$ & $\begin{array}{c}\text { Deviance ratio*, } \\
\text { Time by Isolate } \\
\text { by Frequency by } \\
\text { Inoculation }\end{array}$ & d.f. & $P \dagger$ \\
\hline 1 & JIW9, JIW24 & 0.14 & 1,15 & NS & & & NS \\
2 & JIW9, JIW24 & 1.42 & 1,16 & NS & 0.53 & 2,16 & \\
3 & JIW9, JIW24 & 0.49 & 1,46 & NS & & \\
4 & JIW9, JIW24 & 0.01 & 1,48 & NS & & \\
\hline
\end{tabular}

* Deviance ratio follows an $F$-distribution under the null hypothesis that the deviance associated with a factor can be explained by the residual deviance.

$\uparrow P$-value: NS, not significant $(P>5$ per cent $)$.

Table 3 Results of density-dependent selection experiments on wheat powdery mildew, given as the proportion of white colonies scored (either JIW9 or JIW45)

\begin{tabular}{lclcrc}
\hline Isolates & Experiment & Density & $\begin{array}{c}\text { Proportion } \\
\text { (per cent) }\end{array}$ & $n^{*}$ & $\begin{array}{c}\text { Standard } \\
\text { error }\end{array}$ \\
\hline JIW20, JIW45 & 1 & Low & 28.2 & 13166 & 0.49 \\
& 2 & High & 43.9 & 7727 & 0.27 \\
& 2 & Low & 31.2 & 3061 & 0.80 \\
JIW9, JIW19 & \multirow{2}{*}{3} & High & 43.6 & 2304 & 0.49 \\
& & Low & 10.1 & 7473 & 0.24 \\
& \multirow{2}{*}{4} & High & 15.6 & 8582 & 0.22 \\
JIW9, JIW24 & \multirow{2}{*}{5} & High & 22.4 & 5666 & 0.78 \\
& & Low & 31.9 & 5856 & 0.56 \\
& \multirow{2}{*}{6} & High & 70.2 & 3224 & 0.57 \\
& & Low & 14.8 & 4066 & 0.53 \\
& & High & 45.5 & 1156 & 0.84 \\
\end{tabular}

Average densities were $0.31( \pm 0.19)$ spores $\mathrm{mm}^{-2}$ for low density, and 580 $( \pm 160)$ spores $\mathrm{mm}^{-2}$ for high density.

$*$ Number of colonies scored. 
Table 4 Significance tests for density dependence experiments on wheat powdery mildew

\begin{tabular}{|c|c|c|c|c|c|c|c|}
\hline Experiment & Isolates & $\begin{array}{c}\text { Deviance } \\
\text { ratio } \dagger, \text { Isolate } \\
\text { by Density }\end{array}$ & d.f. & $P$ & $\begin{array}{l}\text { Deviance } \\
\text { ratio } \dagger \text {, Isolate } \\
\text { by Density by } \\
\text { Inoculation }\end{array}$ & d.f. & $P$ \\
\hline 1 & JIW20, JIW45 & 38.99 & 1,24 & $* * *$ & 0.37 & 4,24 & NS \\
\hline 2 & JIW20, JIW45 & 15.83 & 1,16 & $* *$ & 1.78 & 2,16 & NS \\
\hline 3 & JIW9, JIW19 & 45.78 & 1,13 & $* * *$ & 0.65 & 4,13 & NS \\
\hline 4 & JIW9, JIW19 & 42.29 & 1,16 & $* * *$ & 1.39 & 2,16 & NS \\
\hline 5 & JIW9, JIW24 & 145.01 & 1,24 & $* * *$ & 2.05 & 4,24 & NS \\
\hline 6 & JIW9, JIW24 & 21.74 & 1,24 & $* * *$ & 1.10 & 2,24 & NS \\
\hline 7 & JIW9, JIW24 & 15.61 & 1,36 & $* * *$ & & & \\
\hline 8 & JIW9, JIW24 & 5.73 & 1,36 & * & & & \\
\hline
\end{tabular}

${ }^{*} 0.05>P>0.01,{ }^{* *} 0.01>P>0.001, * * P<0.001 ;$ NS, not significant.

†Deviance ratio, see footnotes to Table 2.

Table 5 Estimates of selection coefficients for wheat powdery mildew (positive values indicate selection in favour of the first isolate listed)

\begin{tabular}{clccc}
\hline Experiment & Isolates & Low density & High density & Difference \\
\hline 1 & JIW45, JIW20 & -0.374 & 0.083 & 0.457 \\
2 & JIW45, JIW20 & -0.196 & 0.113 & 0.309 \\
3 & JIW9, JIW19 & -4.62 & -3.52 & 1.10 \\
4 & JIW9, JIW19 & -0.749 & 0.164 & 0.913 \\
5 & JIW9, JIW24 & 0.048 & 0.527 & 0.479 \\
6 & JIW9, JIW24 & -0.608 & 0.185 & 0.793 \\
\hline
\end{tabular}

Table 4 . The Isolate by Density by Inoculation effect was not significant in any of the experiments, which implies that the effects seen in the Isolate by Density level were not just large random deviations. In all the experiments, there was a significant Isolate by Density interaction, suggesting that there was density-dependent selection. The estimates for the selection coefficients are shown in Table 5. In all cases, the coefficients were higher at the higher densities, showing that JIW9 competed better than both JIW19 and JIW24 at the higher rather than lower densities, and JIW45 competed better than JIW20 at the higher density than the lower density.

In the two experiments which used a range of several densities, a linear relationship between $\ln$ $(1-s)$ and $\ln (D)$ ( $D=$ density) was found in both experiments (Fig. 1). There was no significant difference between the two fitted lines, so the data were pooled to give the following expression:

$\ln (1-s)=-0.57+0.17 \ln (D)$.

The direction of the changes in the selection is in accordance with the other experiments (Table 5).

\section{Life history traits}

Comparisons of life history traits were made between the pairs of isolates which were compared with each other in the selection experiments. Differences between isolates were analysed by analysis of variance (ANOVA).

Infection efficiencies are shown in Table 6, and the analysis of variance in Table 7 . The Density by Isolate interaction was not significant, which suggests that the density-dependent selection was unlikely to have been caused by infection ability changing with density. In both pairs of isolates, density had a significant effect on the infection efficiency. However, the infection efficiencies of one pair of isolates, JIW9 and JIW24, were both higher at the high densities, whereas for the other pair, JIW20 and JIW45, they were both lower at the higher densities. Over both densities, JIW20 and JIW45 did not have significantly different infection efficiencies, whereas JIW24 had a significantly higher infection efficiency than JIW9. 
The spore production data are summarized in Tables 6 and 7 . In both cases the Isolate by Density interaction was significant, which suggests that variation in spore production could have caused the

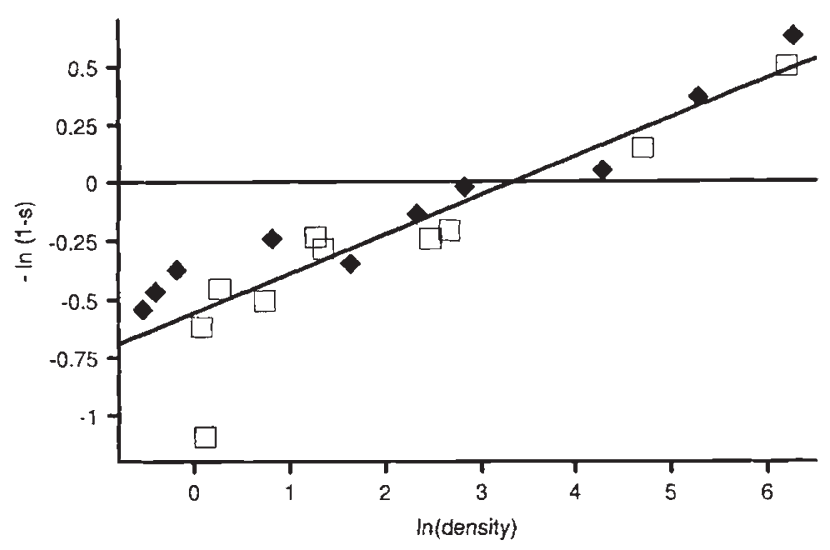

Fig. 1 The relationship between the selection coefficient $(s)$ and density (measured as spores inoculated per $\mathrm{mm}^{2}$ ) for JIW9 against JIW24. $\square-$ Experiment 1, $\bullet$ Experiment 2 . differences in selection coefficients at different densities. JIW24 and JIW20 both produced fewer spores per colony at high densities, whereas the other two isolates (JIW9 and JIW45) did not show a change in spore production with density. In the selection experiments both JIW24 and JIW20 competed less well against JIW9 and JIW45, respectively, at higher densities.

\section{Discussion}

The experiments described here provided no evidence for frequency-dependent selection of $E$. graminis f. sp. tritici grown on detached leaves. Some of the mechanisms for frequency-dependent selection which are advocated involve either sexual selection or selection by predators or pathogens (Maynard Smith, 1989). Under the experimental conditions used, neither of these conditions will have applied. However, competition for resources may also cause frequency-dependent selection if competition between genotypes is different from competition within genotypes (Christiansen, 1988). The

Table 6 Infection efficiencies and spore productions of wheat powdery mildew at different densities

\begin{tabular}{|c|c|c|c|c|c|c|c|c|c|c|}
\hline \multirow[b]{2}{*}{ Isolate } & \multicolumn{5}{|c|}{ Low density } & \multicolumn{5}{|c|}{ High density } \\
\hline & Density* & $n \dagger$ & $\begin{array}{l}\text { Infection } \\
\text { efficiency } \\
\pm \mathrm{SE} \ddagger\end{array}$ & $n \dagger$ & $\begin{array}{c}\text { Spore } \\
\text { production } \\
\pm S E \S\end{array}$ & Density* & $n \dagger$ & $\begin{array}{l}\text { Infection } \\
\text { efficiency } \\
\pm S E \ddagger\end{array}$ & $n^{\dagger}$ & $\begin{array}{l}\text { Spore } \\
\text { production } \\
\pm S E \S\end{array}$ \\
\hline 9 & 0.21 & 42 & $0.090 \pm 0.0652$ & 2 & $5977.8 \pm 3.84$ & 1.71 & 42 & $0.123 \pm 0.0394$ & 2 & $6779.7 \pm 3.84$ \\
\hline 24 & 0.21 & 42 & $0.206 \pm 0.0791$ & 2 & $8262.0 \pm 3.84$ & 1.63 & 42 & $0.139 \pm 0.0265$ & 2 & $7375.1 \pm 3.84$ \\
\hline 20 & 0.75 & 42 & $0.237 \pm 0.1706$ & 2 & $8383.5 \pm 4.27$ & 6.04 & 42 & $0.290 \pm 0.0830$ & 2 & $5977.8 \pm 4.27$ \\
\hline 45 & 0.46 & 42 & $0.220 \pm 0.1165$ & 2 & $8966.7 \pm 4.27$ & 3.00 & 84 & $0.148 \pm 0.0720$ & 2 & $9574.2 \pm 4.27$ \\
\hline
\end{tabular}

*Inoculated spores per $\mathrm{mm}^{-2}$; †number of replicates; $\ddagger$ colonies per inoculated spore; §spores produced per colony.

Table 7 Analysis of variance of infection efficiency and spore production of wheat powdery mildew

\begin{tabular}{|c|c|c|c|c|c|c|c|c|c|c|c|c|c|c|}
\hline \multirow[b]{3}{*}{ Source } & \multicolumn{7}{|c|}{ Infection efficiency } & \multicolumn{7}{|c|}{ Spore production } \\
\hline & \multirow[b]{2}{*}{ d.f. } & \multicolumn{3}{|c|}{ JIW9, JIW24 } & \multicolumn{3}{|c|}{ JIW20, JIW45 } & \multirow[b]{2}{*}{ d.f. } & \multicolumn{3}{|c|}{ JIW9, JIW24 } & \multicolumn{3}{|c|}{ JIW20, JIW45 } \\
\hline & & Variance & $F$ & $P$ & Variance & $F$ & $P$ & & Variance & $F$ & $P$ & Variance & $F$ & $P$ \\
\hline Isolate & 1 & 1.05 & 100.65 & $* * *$ & 0.00648 & 1.08 & NS & 1 & 8206.11 & 23.06 & $* * *$ & 17242.3 & 39.24 & $* *$ \\
\hline Density & 1 & 0.074 & 7.07 & $* *$ & 0.230 & 38.16 & $* * *$ & 1 & 8.26 & 0.02 & NS & 4415.6 & 7.28 & $* * *$ \\
\hline Isolate by Density & 1 & 0.0052 & 0.50 & NS & 0.000307 & 0.05 & NS & 1 & 3836.42 & 10.78 & $* *$ & 8963.7 & 20.40 & $* * *$ \\
\hline Error & 206 & 0.010 & & & 0.00603 & & & 141 & 355.87 & & & 439.5 & & \\
\hline Total & 209 & & & & & & & 144 & & & & & & \\
\hline
\end{tabular}

${ }^{*} 0.05>P>0.01,{ }^{* *} 0.01>P>0.001,{ }^{* * *} P<0.001 ; \mathrm{NS}$, not significant. 
results suggest that this is not the case for E. graminis f. sp. tritici, although the lack of evidence for frequency-dependent selection in our laboratory experiments does not necessarily mean that it does not occur in the field.

We consistently found evidence for densitydependent selection. The selection coefficient can change sign (Table 5, Fig. 1), in other words selection can favour different isolates at different densities. It is therefore possible that density-dependent selection could help to maintain diversity in the mildew populations.

Roughgarden (1971) suggested a form for the way in which fitness changes with density. This is based on the logistic equation, so selection varies linearly with density. Rearranging the expression obtained from the data (Fig. 1) gives

$1-s=0.57 D^{-0.17}$.

This differs from Roughgarden's model, in that density has a large effect on the selection coefficient at lower densities, but changes little above a density of about 50 spores $\mathrm{mm}^{-2}$.

The logistic equation, upon which Roughgarden's (1971) model is based, models changes in population size (i.e. the number of individuals). However, the response of many fungi to an increase in density will not only be a reduction in the number of individuals, but also a reduction in the size of each member of the population, as its space is limited by its neighbours. Most of the change in the selection coefficient occurs over the lower density range, when mature colonies are still distinguishable as individuals, even though they are merging with other colonies. Over this range of densities, the effect of density is not so much on the number of colonies formed, as on their productivity, as shown by the spore production data (Table 6). Rather than Roughgarden's model based on numbers of individuals, a model based on productivity changes may be more appropriate for $E$. graminis.

The life history trait data suggest that densitydependent selection may have been caused by variation in sporulation at different densities. This agrees with the work of Stähle (1986) and Rouse et al. (1984), who also found that different isolates differ in the amount that density affects the ability to sporulate. The simplest explanation for this is that the different isolates differ in their abilities to utilize resources when they are limited at high density, with the isolate that is relatively fitter at higher density using them to produce spores more efficiently. The two densities chosen to study the life history traits correspond to the density range over which the greatest changes in selection occur. At the higher density, individual colonies were distinguishable at about eight to nine days, but were merging after 14 days when the spore counts were taken. It is where colonies meet that competition occurs so the nature of selection will change from $r$ type, caused by differences in growth rate, to $K$ type, caused by competition. This effect is significant over the range of densities at which the life history traits were measured, because it is over this range that the chance of a colony meeting another colony increases most steeply with density. However, this competition is the same between colonies of the same and different clones, so frequency-dependent selection did not occur.

Comparison of the effect of density on infection efficiency between isolates not paired together reveals that there were different reactions to density. JIW9 and JIW24 had higher infection efficiencies at the higher density, the opposite to JIW20 and JIW45. It is therefore possible that had the isolates been paired differently, differences in densitydependent selection between clones could also have been caused by differences in abilities to infect the host at different densities. Both induced resistance and induced susceptibility were shown to occur by Chin et al. (1984). Induced resistance is a very localized event (Martinelli, 1990) and as density increases the chance of two infecting spores being close enough to interact will increase. Differences in infection efficiencies may result from differing abilities of isolates to overcome the already active induced host response.

One unexpected result was that in JIW9 and JIW24 the infection efficiencies were higher at the higher density. A possible explanation for this is that, at higher densities, growth of colonies is faster than at lower densities, because Aust \& Kranz (1974) showed that the latent period was less at higher densities. The numbers of colonies counted (after 7 days) at the low density would have been an underestimate if not all of the colonies were visible at that time in the lower density. If this effect was equal in both of a pair of isolates, then it would not affect the conclusions about the relative effects of density on the two isolates. Alternatively, if this is a real effect, then the resources that the plant uses to fight infection could be limited over the range of densities investigated. For JIW9 and JIW24, the resources could have become depleted, so allowing more infection.

Density-dependent selection was consistently detected in the experiments, so it would seem reasonable to say that it could occur in the field. 
However, the question is then, would it have a significant effect on the natural population? For it to have such an effect the density of mildew would have to change enough to cause the direction or intensity of selection to change significantly. The changes in density-dependent selection observed were sometimes quite large, and in some cases the selection reversed direction (Table 5). Although the high densities used were probably much higher than is likely to occur in the field, most of the difference in selection can be explained by differences between low and medium densities. Densities of mildew change over a growing season, starting with a low initial density, which increases through the season (Rouse et al., 1981). The densities at the base of a leaf can often be enough to cause colonies to merge, which means that densities may be high enough to allow competition to occur. However, towards the tip of the leaf the mildew densities are much lower. Density-dependent effects will therefore probably be patchy in space, as well as variable in time.

\section{Acknowledgements}

This research was supported by a John Innes Foundation research studentship (R. B. O'H.), and the Ministry of Agriculture, Fisheries and Food.

\section{References}

ANTONOVICS, J. AND KAREIVA, P. 1988. Frequency-dependent selection and competition: empirical approaches. Phil. Trans. R. Soc. B, 319, 601-613.

AUST, H. J. AND KRANZ, J. 1974. Einfluss der Konidiendichte auf Keimung, Infektion, Inkubationszeit und Sporulation bei dem echten Mehltau der Gerste (Erysiphe graminis DC f. sp. hordei Marchal). Phytopath. Z., 80, 41-53.

BARRETT, J. A. 1988. Frequency-dependent selection in plant-fungal interactions. Phil. Trans. R. Soc. B, 319, 473-483.

BENNETT, F. G. A. AND VAN KINTS, T. 1982. Mildew of Wheat. UK Cereal Pathogen Virulence Survey 1981 Annual Report, pp. 3-17.

BRADSHAw, W. E. AND HOLZAPFEL, C. M. 1989. Life-historical consequences of density-dependent selection in the pitcher-plant mosquito, Wyeomyia smithii. Am. Nat., 133, 869-887.

BRown, J. K. M. 1994. Chance and selection in the evolution of barley mildew. Trends Microbiol, , 2, 470-475.

BRown, J. K. M. AND wOlFE, M. s. 1990. Structure and evolution of a population of Erysiphe graminis f. sp. hordei. Pl. Pathol., 39, 376-390.

CARVER, T. L. W. AND INGERSON-MORRIS, S. M. 1989. Effects of inoculum density on germling development by Erysiphe graminis f. sp. avenae in relation to induced resistance of oat cells to appressorial penetration. Mycol. Res., 92, 18-24.

CHARLESWORTH, B. 1971. Selection in density regulated populations. Ecology, 52, 469-474.

CHIN, K. M., WOlfE, M. S. AND MINCHIN, P. N. 1984. Hostmediated interactions between pathogen genotypes. $\mathrm{Pl}$. Pathol., 33, 161-171.

CHRISTIANSEN, F. B. 1988. Frequency dependence and competition. Phil. Trans. R. Soc. B, 319, 587-600.

Clarke, B. 1972. Density-dependent selection. Am. Nat, 106, 1-13.

Cox, D. k. 1970. The Analysis of Binary Data. Methuen, London.

FALAHATI-RASTEGAR, M., MANNERS, J, G. AND SMARTT, J. 1981. Effects of temperature and inoculum density on competition between races of Puccinia hordei. Trans. Br. Mycol. Soc., 77, 359-368.

FALAHATI-RASTEGAR, M., MANNERS, J. G. AND SMARTT, J. 1983. Factors determining results of competition between physiologic races of Puccinia hordei. Trans. Br. Mycol. Soc, , 81, 233-239.

HALDANE, J. B. S. 1924. A mathematical theory of natural and artificial selection. Trans. Camb. Phil. Soc., 23, 19-41.

HEDrICK, P. W. 1985. Genetics of Populations. Jones and Bartlett, Boston.

IMHOFF, M. W., LEONARD, K. J. AND MAIN, C. E. 1982. Patterns of bean rust lesion size increase and spore production. Phytopathology, 72, 441-446.

JAYAKAR, s. C. 1970. A mathematical model for interaction of gene frequencies in a parasite and its host. Theor. Pop. Biol. , 1, 140-164.

JøRGENSEN, .. H. 1988. Erysiphe graminis, powdery mildew of cereals and grasses. Adv. Pl. Pathol., 6, 137-157.

LEONARD, K. J. 1969a. Factors affecting rates of stem rust increase in mixed plantings of susceptible and resistant oat varieties. Phytopathology, 59, 1845-1850.

LEONARD, K. J. 1969b. Selection in heterogeneous populations of Puccinia graminis f. sp. avenae. Phytopathology, 59, 1851-1857.

LEONARD, K. J. 1977. Selection pressures and plant pathogens. Ann. N. Y. Acad. Sci, 287, 207-222.

LEWONTIN, R. C. 1955. The effects of population density and composition on viability in Drosophila melanogaster. Evolution, 9, 27-41.

Martinelli, J. A. 1990. Induced Resistance of Barley (Hordeum vulgare L.) to Powdery Mildew (Erysiphe graminis DC.: Fr. $f$. sp. hordei Em. Marchal) and its Potential for Crop Protection. Ph.D. Thesis, University of Cambridge.

MAYNARD SMITh, J. 1989. Evolutionary Genetics. Oxford University Press, Oxford.

McCullagh, P. AND NElder, J. A. 1983. Generalized Linear Models. Chapman and Hall, London.

MUELLER, L. D., GONZÁLEZ-CANDELAS, F. AND SWEET, V. F. 1991. Components of density-dependent population dynamics: models and tests with Drosophila. Am. Nat., 137, 457-475.

(C) The Genetical Society of Great Britain, Heredity, 77, 439-447. 
ROUGHGaRden, J. 1971. Density-dependent natural selection. Ecology, 52, 453-468.

ROUSE, D. 1., MACKENZIE, D. R. AND NELSON, R. R. 1984. Density dependent sporulation of Erysiphe graminis $\mathrm{f}$. sp. tritici. Phytopathology, 74, 1176-1180.

ROUSE, D. 1., MACKENZIE, D. R., NELSON, R. R. AND ELLIOT, V. J. 1981. Distribution of wheat powdery mildew incidence in field plots and relationship to disease severity. Phytopathology, 71, 1015-1020.
STÄHLE, U. 1986. Investigations on the influence of inoculum density on the fitness of races of barley powdery mildew (Erysiphe graminis DC f. sp. hordei Marchal). $Z$. PflKrankh. PflSchutz., 93, 172-176.

WELZ, H. G., NAGARAJAN, S. AND KRANZ, J. 1990. Shortterm virulence dynamics of Erysiphe graminis f. sp. hordei in a single epidemic on two susceptible barley cultivars. Z. PflKrankh. PflSchutz., 97, 250-262. 